\title{
Bioimpedence to Assess Breast Density as a Risk Factor for Breast Cancer in Adult Women and Adolescent Girls
}

\author{
Gertraud Maskarinec $^{1 *}$, Yukiko Morimoto ${ }^{1}$, Michelle B Laguaña ${ }^{2}$, Rachel \\ Novotny ${ }^{3}$, Rachael T Leon Guerrero ${ }^{2}$
}

\begin{abstract}
Although high mammographic density is one of the strongest predictors of breast cancer risk, X-ray based mammography cannot be performed before the recommended screening age, especially not in adolescents and young women. Therefore, new techniques for breast density measurement are of interest. In this pilot study in Guam and Hawaii, we evaluated a radiation-free, bioimpedance device called Electrical Breast Densitometer ${ }^{\mathrm{TM}}$ (EBD; senoSENSE Medical Systems, Inc., Ontario, Canada) for measuring breast density in 95 women aged 31-82 years and 41 girls aged 8-18 years. Percent density (PD) was estimated in the women's most recent mammogram using a computer-assisted method. Correlation coefficients and linear regression were applied for statistical analysis. In adult women, mean EBD and PD values of the left and right breasts were $230 \pm 52$ and $226 \pm 50 \Omega$ and $23.7 \pm 15.1$ and $24.2 \pm 15.2 \%$, respectively. The EBD measurements were inversely correlated with PD $\left(r_{\text {Spearman }}=-0.52, \mathbf{p}<0.0001\right)$; the correlation was stronger in Caucasians $\left(r_{\text {Spearman }}=-0.70, \mathbf{p}<0.0001\right)$ than Asians $\left(r_{\text {Spearman }}=-\mathbf{0 . 5 4}, \mathbf{p}<0.01\right)$ and Native Hawaiian/Chamorro/Pacific Islanders $\left(r_{\text {Spearman }}=-0.34, p=0.06\right)$. Using 4 categories of $P D(<10,10-25,26-50,51-75 \%)$, the respective mean EBD values were $256 \pm 32,249 \pm 41,202 \pm 46$, and $178 \pm 43$ $\Omega(p<0.0001)$. In girls, the mean EBD values in the left and right breast were $148 \pm 40$ and $155 \pm 54 \Omega$; EBD values decreased from Tanner stages 1 to $4(204 \pm 14,154 \pm 79,136 \pm 43$, and $119 \pm 16 \Omega$ for stages $1-4$, respectively) but were higher at Tanner stage $5(165 \pm 30 \Omega)$. With further development, this bioimpedance method may allow for investigations of breast development among adolescent, as well as assessment of breast cancer risk early in life and in populations without access to mammography.
\end{abstract}

Keywords: Mammography - breast density - bioimpedance - breast cancer - risk assessment - adolescence

Asian Pac J Cancer Prev, 17 (1), 65-71

\section{Introduction}

Breast density is thought to reflects the proliferative activity in the breast, and higher density is one of the strongest predictors of breast cancer risk (Boyd et al., 2005). Known breast cancer risk factors, such as age at menarche, menopausal status, parity, age at first childbirth, and body mass index (BMI), are associated with breast density. Hormone therapy (HT), especially combined estrogen-progestin therapy, appears to increase breast cancer risk as well as breast density (Martin et al., 2009).

Adding mammographic density to breast cancer risk prediction models has been shown to improve the models to a small degree (Tice et al., 2008) and may help to personalize breast cancer screening instead of providing the same recommendations to women at different risk levels (U.S.Preventive Services Task Force, 2009). Moreover, growing evidence also suggests that breast cancer risk is determined early in life, possibly attributed to dietary intake and other lifestyle factors through childhood
(Michels and Willett, 2004). Measuring breast density in young women and girls during pubertal development may provide further insight into breast cancer etiology and prevention; however, because of the relatively high radiation dose, mammography cannot be performed before the recommended screening age. Low- or no-radiation methods, such as Dual Energy X-ray Absorptiometry (DXA) (Maskarinec et al., 2011a) or magnetic resonance imaging (MRI) (Boyd et al., 2009) are viable alternatives but, due to the high costs, are not suitable for large population-based and longitudinal studies.

In this pilot study among the multiethnic population of Guam and Hawaii, we evaluated a radiation-free, bioimpedance technology called Electrical Breast Densitometer $^{\mathrm{TM}}$ (EBD), a novel breast density measurement tool. The primary objectives were to compare the EBD measurements to mammographic densities in adult women and to evaluate the feasibility of measuring breast density in young girls across Tanner stages of pubertal development using this tool (Tanner, 1962).

${ }^{I}$ Epidemiology Program, University of Hawaii Cancer Center, Honolulu, HI, ${ }^{2}$ College of Natural \& Applied Sciences, University of Guam, Guam, ${ }^{3}$ Human Nutrition, Food and Animal Science Department, University of Hawaii, Honolulu, HI, USA *For correspondence: gertraud@cc.hawaii.edu 


\section{Materials and Methods}

Study design and procedures

We recruited adult women aged 30 years and older who had received a normal mammogram on at least one breast during the last 2 years and girls aged 8-18 years with some breast development. In Guam, women and girls were recruited from an ongoing research project, the Development of a Breast Cancer Risk Model for the Pacific (BRISK) study (Leon Guerrero et al., 2014). In Hawaii, eligible women and girls were recruited through the university community, local hospitals, and social media. Attempts were made to recruit mothers and daughters, but we also accepted individual women and girls who met the eligibility criteria. The project was approved by the Western Institutional Review Board and the Institutional Review Board of University of Guam.

After screening interested participants by phone, an appointment at the Clinic at the University of Guam or the University of Hawaii Cancer Center was scheduled. We excluded women who were pregnant or who had no mammogram and girls without breast development. During the visit, written informed consent from the adult women and assent from the adolescent girls, as well as consent from the girls' mothers, were obtained. In addition, the adult women completed a mammogram release form to allow retrieval of their most recent mammographic image. Both women and girls answered a brief questionnaire about demographic, medical, and reproductive factors. Body weight, height, and transverse breast width were measured. Girls also completed Tanner stage assessment of breast and pubic hair development.

\section{EBD data collection}

The concept of bioimpedance has been used for many years as a low cost, portable method to assess body fat. Specifically, body fat analyzers, i.e., simple, foot-to-foot impedance meters with plantar electrodes on a body scale, applied in the development of EBD, have been compared with medical impedance meters and with DXA measurements and found reasonably accurate except in individuals with very low or very high BMI (Jaffrin, 2009). Because fat has 8 times higher impedance than breast and stromal tissue, the EBD method has the ability to evaluate the relative distribution of different tissue types. Contrary to mammographic PD, which increases with higher proportion of dense tissues in the breasts, impedancebased resistance values are lower in dense breasts and higher in breasts with large amounts of adipose tissue.

After changing into an exam gown, EBD-based density was measured in women and girls by a female research staff member who had been trained by a representative of the manufacturer (senoSENSE Medical Systems, Inc., Ontario, Canada). First, a sensor was applied across one breast at a time (Figure 1). The breast density measurement was automatically determined using a portable controller and expressed in ohm $(\Omega)$. Duplicate measurements were obtained to evaluate the reproducibility of the method. The two values for the right and the left breast were averaged.

Mammographic data collection. Craniocaudal (CC) views of screening mammograms taken within the last
2 years were used for women in the current study. We obtained film images for 11 women (9 Guam and 11 Hawaii) and digital images for 82 women (12 Guam and 70 Hawaii). Mammograms for two women in Hawaii could not be retrieved and were recorded as missing data. All personal identifiers were removed from the scanned images. One of the authors (GM) performed computerassisted density assessment using the Cumulus package (Boyd et al., 1998; Byng et al., 1998); all mammograms for one woman were assessed during the same session. Using this interactive method, the reader selects a threshold value (gray scale on the screen) that best distinguishes the breast from the dark background and another threshold value, the gray value that best identifies the edges of the mammographically dense areas within the breast outline. The number of pixels in the two areas is then measured by the computer. The mammographic measures for our analysis included the total breast area and the dense area of the breast; percent density (PD) for each breast was calculated as the ratio of dense to total breast area. Nondense area was calculated as total breast area minus dense area. In a sample of 28 duplicate readings, the correlations were 0.99 for the size of the total breast area, 0.97 for the dense breast area resulting in a correlation of 0.98 for PD.

\section{Statistical Analysis}

All statistical analyses were performed using the

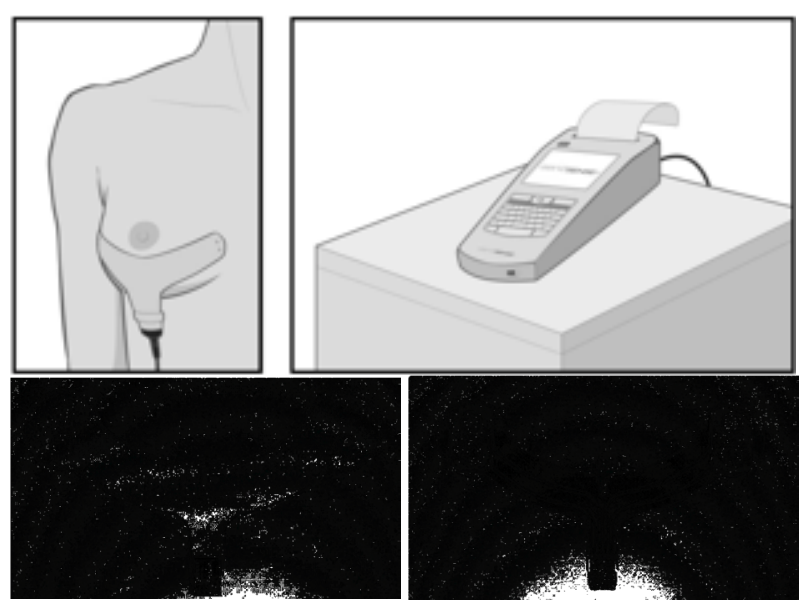

Figure 1. Electrical Breast Densitometer ${ }^{\mathrm{TM}}$ by senoSENSE Medical Systems, Inc. Application to the breast (top) and sensor views from front (bottom left) and back (bottom right)
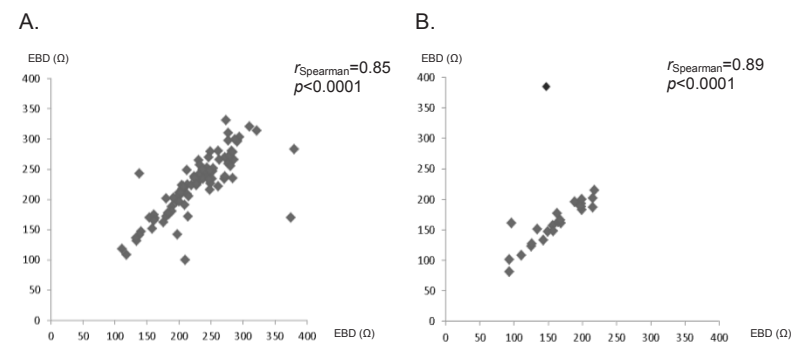

Figure 2. Comparison of left and Right Breast Electrical Breast Densitometer ${ }^{\mathrm{TM}}$ (EBD) Measurements in (A) adult women and (B) girls. Based on 95 women and 40 girls; data are missing for 1 girl in Hawaii 
SAS statistical software package version 9.3 (SAS Institute, Inc., Cary, NC) with a two-sided $p$ value of $<0.05$ considered statistically significant. Because of the small sample size, study participants were grouped into 4 major ethnic categories found in Hawaii and Guam: Asian (Japanese, Filipino, Chinese, Korean, and Other Asian); Caucasian; Native Hawaiian, Chamorro and Other Pacific Islander (PI); and Other (Hispanic and Native Americans). Women whose last menstrual period was $>1$ year ago were classified as postmenopausal. In women and girls, we computed Spearman rank order correlation coefficients between the left and right EBD values. For women, we also estimated the correlation of EBD and PD measurements before and after stratification by ethnic category and after excluding the 11 women with film images. Additionally, we categorized women by mean PD of the left and right breasts into $<10 \%, 10-$ $25 \%, 26-50 \%$ and $\geq 51 \%$ (Yaffe, 2008) and examined the association with EBD measurements. We evaluated the associations of EBD measurements and PD with $\mathrm{BMI}$ and reproductive characteristics, which have been linked with breast cancer risk, i.e., age at menarche $(<13$ $v s . \geq 13$ years), parity (yes $v s$. no), age at first live birth $(\leq 25 v s .>25$ years $)$, number of children $(0,1-2$, and $\geq 3)$,

Table 1. Characteristics of Study Participants*

\begin{tabular}{|c|c|c|c|c|c|c|c|}
\hline & & \multicolumn{2}{|c|}{ Guam } & \multicolumn{2}{|c|}{ Hawaii } & \multicolumn{2}{|c|}{ Total } \\
\hline & & Women & Girls & Women & Girls & Women & Girls \\
\hline $\mathrm{N}$ & & 21 & 15 & 74 & 26 & 95 & 41 \\
\hline Age, years & & $53.2 \pm 8.3$ & $12.8 \pm 2.7$ & $54.4 \pm 11.5$ & $14.7 \pm 3.4$ & $54.1 \pm 10.8$ & $14.0 \pm 3.2$ \\
\hline Body mass index (BMI), $\mathrm{kg} / \mathrm{m}^{2}$ & & $33.6 \pm 9.1$ & $25.9 \pm 10.9$ & $28.6 \pm 7.9$ & $22.9 \pm 4.9$ & $29.7 \pm 8.4$ & $24.0 \pm 7.7$ \\
\hline BMI z-score & & -- & $0.96 \pm 1.28$ & -- & $0.57 \pm 0.91$ & -- & $0.71 \pm 1.06$ \\
\hline \multirow{6}{*}{ Ethnicity, $\mathrm{N}$} & Asian & $1(5 \%)$ & $0(0 \%)$ & $29(39 \%)$ & $11(42 \%)$ & $30(32 \%)$ & $11(27 \%)$ \\
\hline & Chamorro & $16(76 \%)$ & $12(80 \%)$ & $1(2 \%)$ & $0(0 \%)$ & $17(18 \%)$ & $12(29 \%)$ \\
\hline & Native Hawaiian & $0(0 \%)$ & $0(0 \%)$ & $15(20 \%)$ & $15(58 \%)$ & $15(16 \%)$ & $15(37 \%)$ \\
\hline & $\begin{array}{l}\text { Other Pacific } \\
\text { Islander }\end{array}$ & $1(5 \%)$ & $3(20 \%)$ & $0(0 \%)$ & $0(0 \%)$ & $1(1 \%)$ & $3(7 \%)$ \\
\hline & White & $3(14 \%)$ & $0(0 \%)$ & $23(31 \%)$ & $0(0 \%)$ & $26(27 \%)$ & $0(0 \%)$ \\
\hline & Other & $0(0 \%)$ & $0(0 \%)$ & $6(8 \%)$ & $0(0 \%)$ & $6(6 \%)$ & $0(0 \%)$ \\
\hline \multirow{3}{*}{ Menarche, $\mathrm{N}$} & Not yet & -- & $5(36 \%)$ & -- & $4(15 \%)$ & -- & $9(22 \%)$ \\
\hline & $<13$ years & $13(62 \%)$ & $9(60 \%)$ & $49(66 \%)$ & $15(58 \%)$ & $62(65 \%)$ & $24(59 \%)$ \\
\hline & $\geq 13$ years & $8(38 \%)$ & $1(4 \%)$ & $25(34 \%)$ & $7(27 \%)$ & $33(35 \%)$ & $8(19 \%)$ \\
\hline Parity, $\mathrm{N}$ & & $19(90 \%)$ & -- & $51(69 \%)$ & -- & $70(74 \%)$ & -- \\
\hline \multirow{2}{*}{ Number of children } & $1-2$ & $9(43 \%)$ & -- & $31(42 \%)$ & -- & $40(42 \%)$ & -- \\
\hline & $\geq 3$ & $10(48 \%)$ & -- & $20(27 \%)$ & -- & $30(32 \%)$ & -- \\
\hline Age at first child birth, years & & $25.2 \pm 6.1$ & -- & $25.2 \pm 5.8$ & -- & $25.2 \pm 5.9$ & -- \\
\hline Post-menopause, $\mathrm{N}^{* *}$ & & $12(57 \%)$ & -- & $20(27 \%)$ & -- & $32(34 \%)$ & -- \\
\hline \multirow{5}{*}{$\begin{array}{c}\text { Tanner stage of breast } \\
\text { development, } \mathrm{N}\end{array}$} & 1 & -- & $1(7 \%)$ & -- & $3(12 \%)$ & -- & $4(10 \%)$ \\
\hline & 2 & -- & $3(20 \%)$ & -- & $1(4 \%)$ & -- & $4(10 \%)$ \\
\hline & 3 & -- & $4(26 \%)$ & -- & $8(31 \%)$ & -- & $12(29 \%)$ \\
\hline & 4 & -- & $1(7 \%)$ & -- & $4(15 \%)$ & -- & $5(12 \%)$ \\
\hline & 5 & -- & $6(40 \%)$ & -- & $10(38 \%)$ & -- & $16(39 \%)$ \\
\hline \multirow{5}{*}{$\begin{array}{c}\text { Tanner stage of pubic hair } \\
\text { development, } \mathrm{N}\end{array}$} & 1 & -- & $3(20 \%)$ & -- & $2(8 \%)$ & -- & $5(12 \%)$ \\
\hline & 2 & -- & $2(13 \%)$ & -- & $2(8 \%)$ & -- & $4(10 \%)$ \\
\hline & 3 & -- & $2(13 \%)$ & -- & $3(11 \%)$ & -- & $5(12 \%)$ \\
\hline & 4 & -- & $4(27 \%)$ & -- & $8(31 \%)$ & -- & $12(29 \%)$ \\
\hline & 5 & -- & $4(27 \%)$ & -- & $11(42 \%)$ & -- & $15(37 \%)$ \\
\hline \multirow{2}{*}{$\begin{array}{c}\text { Electrical Breast } \\
\text { Densitometer }{ }^{\mathrm{TM}}(\mathrm{EBD}) \\
\text { measurement }{ }^{*}, \Omega\end{array}$} & Left & $245 \pm 65$ & $148 \pm 40$ & $226 \pm 48$ & $148 \pm 42$ & $230 \pm 52$ & $148 \pm 4.0$ \\
\hline & Right & $221 \pm 46$ & $167 \pm 70$ & $228 \pm 51$ & $147 \pm 40$ & $226 \pm 50$ & $155 \pm 54$ \\
\hline \multirow{2}{*}{$\begin{array}{c}\text { Mammographic density***, } \\
\%\end{array}$} & Left & $29.5 \pm 15.8$ & -- & $22.0 \pm 14.5$ & -- & $23.7 \pm 15.1$ & -- \\
\hline & Right & $30.5 \pm 16.6$ & -- & $22.5 \pm 14.4$ & -- & $24.2 \pm 15.2$ & -- \\
\hline
\end{tabular}

*Data are presented as mean \pm standard deviation or N (\%). Mean EBD measurements are calculated based on 95 women and 40 girls; data are missing for 1 girl in Hawaii; **Women are categorized as post-menopausal if their last menstrual periods were $>1$ year ago; $* * *$ Mean mammographic densities are based on 93 women (72 in Hawaii and 21 in Guam); data are missing for 2 women in Hawaii 
and menopausal status (yes vs. no), using generalized linear models. In girls, means and standard deviations of EBD-based density were calculated by Tanner stage of breast. Using linear regression, we modeled the change in breast density across Tanner stage and other factors, such as age, menarche (yes vs. no), ethnicity, and BMI z-score. The BMI z-score was calculated based on the Centers for Disease Control's reference data (Centers for Disease Control and Prevention/National Center for Health Statistics, 2009).

\section{Results}

A total of 95 women (21 from Guam and 74 from Hawaii) and 41 girls ( 15 from Guam and 26 from Hawaii) participated in the study (Table 1). Seven women reported having had breast cancer and partial lumpectomy on one breast. Based on self-declared primary ethnicity, $32 \%$ of all adult women were Asian, $27 \%$ Caucasian, $35 \%$ PI, and $6 \%$ Other; the respective proportions for girls were $27 \%$ Asian and $73 \%$ PI. Mean ages and BMIs of adult women and girls were $54.1 \pm 10.8$ years and $14.0 \pm 3.2$ years and $29.7 \pm 8.4 \mathrm{~kg} / \mathrm{m}^{2}$ and $24.0 \pm 7.7 \mathrm{~kg} / \mathrm{m}^{2}$, respectively. Mean BMI z-score for the girls was $0.71 \pm 1.06$. Mean BMI of adult women differed significantly by ethnicity $(\mathrm{p}<0.01$; Table 2). PI women had the highest mean BMI (29.7 \pm 9.5 $\left.\mathrm{kg} / \mathrm{m}^{2}\right)$ followed by Caucasians $\left(28.3 \pm 9.1 \mathrm{~kg} / \mathrm{m}^{2}\right)$ and Others $\left(27.3 \pm 7.6 \mathrm{~kg} / \mathrm{m}^{2}\right)$, and the Asian women had the lowest mean BMI $\left(27.0 \pm 6.2 \mathrm{~kg} / \mathrm{m}^{2}\right)$. Similarly, in girls, mean BMI z-score was higher among PIs than Asians $(0.97 \pm 1.06$ vs. $0.01 \pm 0.68, \mathrm{p}<0.01)$. Of the 41 girls, 32 (78\%) had reached menarche prior to study enrollment (Table 1); the respective number of girls by Tanner breast stages $1-5$ were $4,2,12,5$, and 16 .

Mean EBD and PD values of the left and right breasts in all adult women were $230 \pm 52$ and $226 \pm 50 \Omega$ and $23.7 \pm 15.1$ and $24.2 \pm 15.2 \%$, respectively. These values changed very little after excluding the 7 women with a history of breast cancer $(231 \pm 54$ and $228 \pm 50 \Omega$ and $24.0 \pm 15.4$ and $24.7 \pm 15.5 \%$ ). The mean EBD values in girls were $148 \pm 40$ and $155 \pm 54 \Omega$ for the left and right breasts. The duplicate EBD measurements of each breast $\left(r_{\text {Spearman }}=-0.99\right.$ for all, $\mathrm{p}<0.0001)$, as well as the mean EBD measurements of the left and right breasts $\left(\mathrm{r}_{\text {Spearman }}=-0.89-0.85, \mathrm{p}<0.0001\right.$; Figure 2), were highly correlated in adult women and in girls. The dense and non-dense mammographic areas of adult women were non-significantly inversely associated $\left(\mathrm{r}_{\text {Spearman }}=-0.05, \mathrm{p}<0.61\right)$, whereas the non-dense areas showed a high correlation with EBD measurements $\left(\mathrm{r}_{\text {Spearman }}=-0.30, \mathrm{p}<0.01\right)$ with EBD measurements.

Among adult women, mean EBD measurements were significantly inversely correlated with mean PD $\left(\mathrm{r}_{\text {Spearman }}=-0.52, \mathrm{p}<0.0001\right)$ with some ethnic variation (Table 2 and Figure 3); the correlation was higher in Caucasians $\left(\mathrm{r}_{\text {Spearman }}=-0.70, \mathrm{p}<0.0001\right)$ and Others $\left(\mathrm{r}_{\text {Spearman }}=-0.83, \mathrm{p}=0.04\right)$ than Asians $\left(\mathrm{r}_{\text {Spearman }}=-0.54\right.$, $\mathrm{p}<0.01)$ and PIs $\left(\mathrm{r}_{\text {Spearman }}=-0.34, \mathrm{p}=0.06\right)$. However, no statistically significant ethnic differences in EBD or PD were detected before and after adjustment for age and BMI. Results were similar when we restricted the analyses

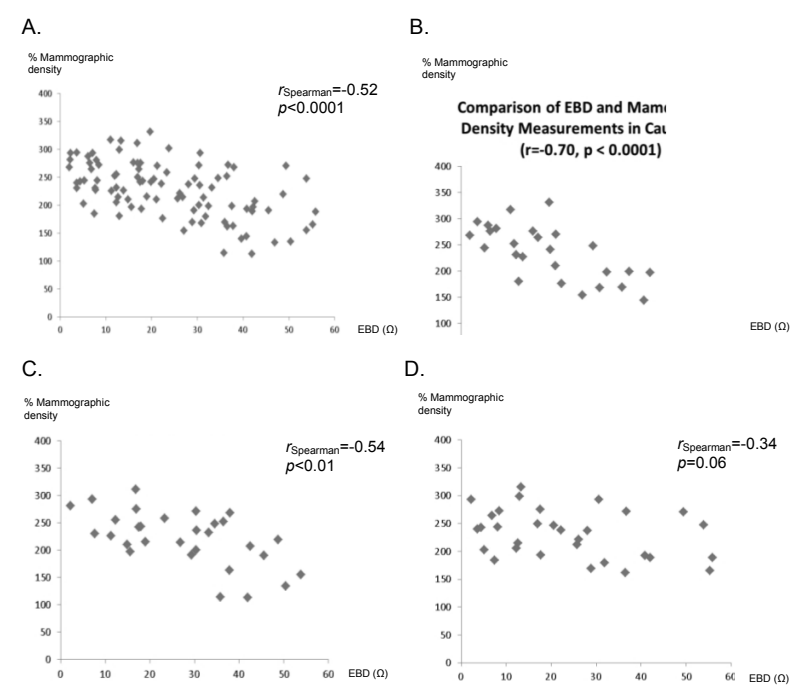

Figure 3. Comparison of Electrical Breast Densitometer $^{\mathrm{TM}}$ (EBD) and mammographic density measurements in (A) all women; (B) Caucasians; (C) Asians; and (D) Native Hawaiians, Chamorros, and other Pacific Islanders. Based on 93 mammograms obtained; data are missing for 2 women in Hawaii

Table 2. Correlations between Electrical Breast Densitometer ${ }^{\mathrm{TM}}$ (EBD) measurement and mammographic density in adult women by ethnic category*

\begin{tabular}{|cccccccc|}
\hline Ethnicity & $\mathrm{N}$ & Age (years) & $\begin{array}{c}\text { Body mass } \\
\text { index }\left(\mathrm{kg} / \mathrm{m}^{2}\right)\end{array}$ & $\mathrm{EBD}(\Omega)$ & $\begin{array}{c}\text { Mammographic } \\
\text { density }(\%)\end{array}$ & $\mathrm{r}_{\text {Spearman }}$ & P value \\
\hline Caucasian & 26 & $60.0 \pm 10.6$ & $28.3 \pm 9.1$ & $235 \pm 52$ & $19.5 \pm 11.9$ & -0.7 & $<0.0001$ \\
\hline Asian & 30 & $55.5 \pm 11.7$ & $27.0 \pm 6.2$ & $222 \pm 50$ & $27.6 \pm 14.0$ & -0.54 & $<0.01$ \\
\hline $\begin{array}{c}\text { Native Hawaiian, Chamorro, } \\
\text { and Other Pacific Islander }\end{array}$ & 31 & $50.0 \pm 7.5$ & $34.1 \pm 8.2$ & $232 \pm 43$ & $23.7 \pm 16.3$ & -0.34 & 0.06 \\
\hline Other & 6 & $48.2 \pm 9.4$ & $27.3 \pm 7.6$ & $218 \pm 63$ & $25.5 \pm 17.3$ & -0.83 & 0.04 \\
\hline All women & 93 & $54.4 \pm 10.7$ & $29.7 \pm 8.3$ & $228 \pm 48$ & $23.9 \pm 14.6$ & -0.52 & $<0.0001$ \\
\hline $\begin{array}{c}\text { P value for ethnic differences, } \\
\text { unadjusted** }\end{array}$ & $<0.01$ & $<0.01$ & 0.41 & 0.28 & & \\
\hline $\begin{array}{c}\text { P value for ethnic difference, } \\
\text { adjusted** }\end{array}$ & & & 0.84 & 0.05 & & \\
\hline
\end{tabular}

*Based on 93 mammograms (72 in Hawaii and 21 in Guam) obtained; data are missing for 2 women in Hawaii;**Comparisons of ethnic groups (categorical) in EBD or mammographic density measurements (log-transformed, continuous) were performed using generalized linear model with 


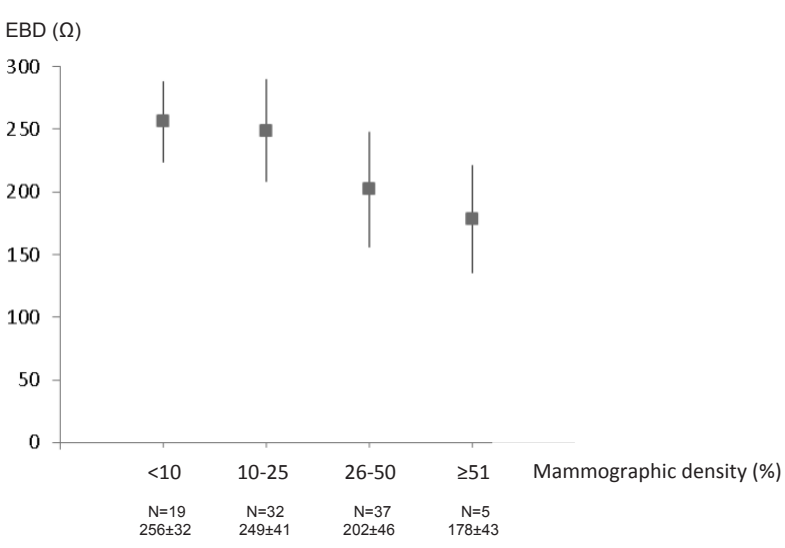

Figure 4. Mean Electrical Breast Densitometer ${ }^{\mathrm{TM}}$ (EBD) Measurement of the Left and Right Breasts in Adult Women by Percent Mammographic Density Category. Based on 93 mammograms obtained; data are missing for 2 women in Hawaii

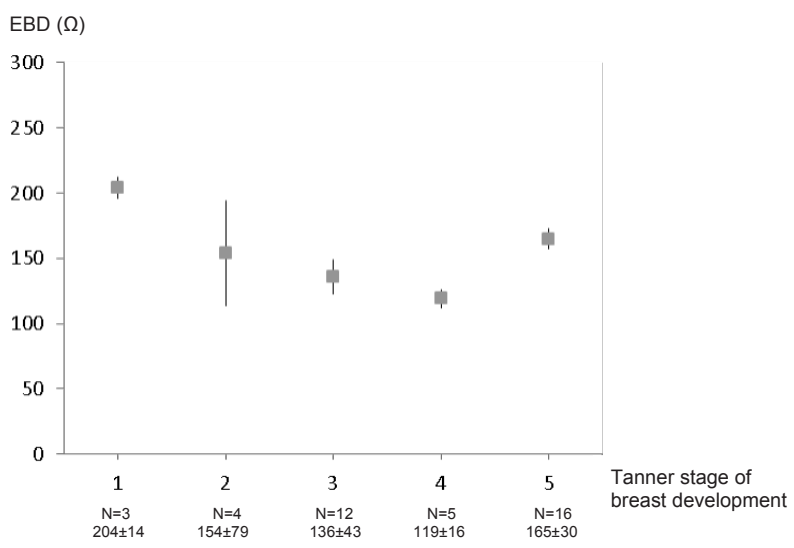

Figure 5. Mean Electrical Breast Densitometer ${ }^{\mathrm{TM}}$ (EBD) Measurement of the left and Right Breasts in Girls by Tanner Stage of Breast Development. Based on 40 girls; data are missing for 1 girl in Hawaii

to the 82 women with digital mammograms and excluded 11 women with film images or excluded the 7 women with a history of breast cancer and partial lumpectomy. Neither EBD nor PD measurements were associated with age at menarche, parity, age at first live birth, number of children, or menopausal status. Using the four PD categories, a statistically significant inverse association $(p<0.001)$ with EBD measures before and after adjustment for age and BMI was seen; the unadjusted mean EBD values for the lowest to highest PD categories were $256 \pm 32,249 \pm 41$, $202 \pm 46$, and $178 \pm 43 \Omega$ (Figure 4).

In girls, the mean EBD values were lower with higher Tanner breast stages of $(204 \pm 14,154 \pm 79,136 \pm 43$, and $119 \pm 16 \Omega$ for stages 1 to 4 , respectively; Figure 5) but higher at Tanner stage $5(165 \pm 30 \Omega)$. A similar trend was observed with Tanner stages of pubic hair development (data not shown). Between the two ethnic categories, the PI group had a higher mean EBD value than the Asians $(161 \pm 44$ vs. $128 \pm 32 \Omega ; \mathrm{p}=0.03)$, which remained statistically significant after adjustment for Tanner breast stage ( $\mathrm{p}=0.03$ ); however, when adjusted for age, menarche and BMI z-score, this difference was no longer significant.

\section{Discussion}

In this pilot study, EBD measurements in adult women showed a significant inverse association with increasing PD categories. Across ethnic groups, EBD measurements were strongly inversely associated with recent mammographic density measurements in Caucasian women, whereas the associations were weaker for Asian and PI women. Among girls, a decrease in mean EBD values from Tanner breast stages 1 to 4 and an increase at Tanner stage 5 indicate a change from adipose to denser tissue until stage 4 and further fat accumulation during stage 5. With further testing and development, this portable, no-radiation device may provide a useful research tool to measure breast density in populations of adult women and girls and allow for evaluation of breast cancer risk early in life, as well as in remote populations who do not have access to screening mammography.

Limitations of this feasibility study include the use of different mammography systems across the radiology facilities. A majority of the clinics used digital mammography (88\%), but $12 \%$ were film images. Another technical issue was the large size of the sensor, which was originally developed for adult Caucasian women (Bukhanov et al., 2012). In this multiethnic population with a large proportion of Asian women, as well as girls with small body frames, the one-size-fits-all size of the sensor may have reduced the comparability of the measurements across women and contributed to the differences in correlations across ethnic group. The size of the study population was small, especially for girls, and after stratification by ethnic category and menopausal status. Therefore, differential correlations by ethnic group between PD and EBD could not be explained by covariates in the regression models. Thus, the sensor needs to be further evaluated in women and girls with different ancestries and body sizes. Due to the cross-sectional study design, it was also not possible to show that EBD-based values differ between women with and without breast cancer. The use of a convenience sample and the restriction to adult women with a recent mammogram likely added selection bias. The study probably attracted women and girls who have higher awareness about breast cancer risk. In fact, a small proportion of women were breast cancer survivors with partial lumpectomies. Despite this small number of cancer survivors in the pilot study, due to the limited sample size, we were not able to evaluate the association of EBD measurements with breast cancer risk at this time. It is important that a direct relationship is demonstrated in future evaluations to substantiate the potential application of this novel technology.

The current study also had strengths including its multiethnic population with different breast cancer incidence rates (Hernandez, 2002) and the inclusion of girls across Tanner stages of breast development. While the sensor, including its uniform size, needs to be further validated, this new assessment method, which requires no breast compression, was well tolerated by all women and girls. The EBD measurement of girls across Tanner breast stages reflected the transitional changes in adiposity and 
dense tissues in the breast during pubertal development. Interestingly, ethnic differences in EBD measurement remained significant after adjustment for Tanner breast stages. More EBD measurements, if collected in girls, may provide additional information to further explore breast density in relation to other early-life breast cancer risk factors and ethnic influences. The simplicity of operation and lack of radiation exposure make this portable device a potential research tool in large cross-sectional and longitudinal studies of breast cancer risk. With additional testing, the EBD method may also offer an additional screening tool to women who have limited access to mammography and girls and young women below the recommended screening age for mammography.

A number of different methods are currently under investigation to examine breast density without radiation including MRI (Boyd et al., 2009) and ultrasound tomography (Glide et al., 2007; Glide-Hurst et al., 2008). We previously investigated the use of DXA as a low-radiation method to measure breast density in mother-daughter pairs and reported a correlation of 0.76 $(\mathrm{p}<0.0001)$ between DXA and mammographic percent density (Maskarinec et al., 2011b). While DXA devices are widely available in hospitals and clinics and, similar to EBD, require no breast compression, the EBD method has the advantage of very low cost, light weight, portability, and no need for a specialized technician. A Canadian study evaluated the use of MRI in mother-daughter pairs and found a strong correlation $(r=0.85, p<0.0001)$ of percent breast water as surrogate for fibroglandular tissue with PD among the mothers (Boyd et al., 2009). In comparison to the DXA and the MRI report, the current study detected a lower correlation $\left(\mathrm{r}_{\text {Spearman }}=-0.52, \mathrm{p}<0.0001\right)$ between EBD measurements and PD in a smaller sample $(\mathrm{N}=93)$ of women, which stresses the need for additional evaluation and development of the EBD device. Nevertheless, in agreement with the MRI findings in daughters with a mean age of 20.8 years, we also observed higher breast density, measured as lower EBD measurements, in adolescent girls than in adult women. Moreover, the findings in girls showed a similar pattern of change in breast development across Tanner breast stages as the DXA study (Novotny et al., 2011). Both studies suggest breast density increases from Tanner breast stages 1 to 4 and decreases in stage 5 . This finding may reflect an acceleration of adipose tissue accumulation in Tanner stage 5. Given the small sample size, this non-linear pattern needs to be further examined; however, if confirmed, this study may add new information to our limited understanding about the adipose and dense tissue formation in the breast during pubertal maturation.

With further development, this bioimpedance method may allow for assessment of breast cancer risk early in life and in populations without access to mammography. In particular for longitudinal studies examining change in breast density over time, this radiation-free and inexpensive method may offer opportunities not provided by DXA and MRI imaging. Given the lack of mammography across many Pacific Islands and other remote communities, it may also be possible to stratify women by breast cancer risk using the EBD tool and provide regular exams to the women at high risk. The major challenge is to develop optimal risk prediction models that discriminate between low and high risk women more efficiently than the current models (Gail et al., 1999; Tice et al., 2005).

\section{Acknowledgements}

Authors declare no conflict of interest. The current project was supported by grant U54 CA143727 from the National Cancer Institute. We thank all women and girls who participated in this study.

\section{References}

Boyd N, Martin L, Chavez S, et al (2009). Breast-tissue composition and other risk factors for breast cancer in young women: a cross-sectional study. Lancet Oncol, 10, 569-80.

Boyd NF, Lockwood GA, Byng JW, et al (1998). The relationship of anthropometric measures to radiological features of the breast in premenopausal women. Br J Cancer, 78, 1233-8.

Boyd NF, Rommens JM, Vogt K, et al (2005). Mammographic breast density as an intermediate phenotype for breast cancer. Lancet Oncol, 6, 798-808.

Bukhanov K, Ironstone J, Basso C, Bilodeau T (2012). Determination of breast density by bioimpedance (abstract, Breast Cancer Symposium). http://meetinglibrary.asco.org/ content/102867-125. Accessed on 1-31-2013.

Byng JW, Yaffe MJ, Jong RA, et al (1998). Analysis of mammographic density and breast cancer risk from digitized mammograms. Radiographics, 18, 1587-98.

Centers for Disease Control and Prevention/National Center for Health Statistics, 2009. CDC Growth Charts. www.cdc.gov/ growthcharts. Accessed on 6-22-2010.

Gail MH, Kessler L, Midthune D, et al (1999). Two approaches for estimating disease prevalence from population-based registries of incidence and total mortality. Biometrics, $\mathbf{5 5}$, 1137-44.

Glide C, Duric N, Littrup P (2007). Novel approach to evaluating breast density utilizing ultrasound tomography. Med Phys, 34, 744-53.

Glide-Hurst CK, Duric N, Littrup P (2008). Volumetric breast density evaluation from ultrasound tomography images. Med Phys, 35, 3988-97.

Hernandez BY (2002). The hawaii tumor registry: more than forty years of cancer surveillance for the islands. Hawaii Med J, 61, 53.

Jaffrin MY (2009). Body composition determination by bioimpedance: an update. Curr Opin Clin Nutr Metab Care, 12, 482-6.

Leon Guerrero RT, Badowski G, Yamanaka A, et al (2014). University of hawai'i cancer center connection: the vital role of cancer registries in the recruitment of an understudied minority population into a breast cancer study: breast cancer risk model for the pacific. Hawaii J Med Public Health, 73, 335-40.

Martin LJ, Minkin S, Boyd NF (2009). Hormone therapy, mammographic density, and breast cancer risk. Maturitas, 64, 20-6.

Maskarinec G, Morimoto Y,Daida Y, et al (2011a). Comparison of breast density measured by dual energy X-ray absorptiometry with mammographic density among adult women in Hawaii. Cancer Epidemiol, 35, 188-93.

Maskarinec G, Morimoto Y, Daida Y, et al (2011b). A comparison of breast density measures between mothers and adolescent daughters. BMC Cancer, 11, 330 .

Michels KB, Willett WC (2004). Breast cancer--early life matters. N Engl J Med, 351, 1679-81. 
Novotny R, Daida Y, Morimoto Y, et al (2011). Puberty, body fat, and breast density in girls of several ethnic groups. Am J Hum Biol, 23, 359-65.

Tanner JM (1962). Growth at adolescence, with a general consideration of the effects of hereditary and environmental factors upon growth and maturation from birth to maturity. $2^{\text {nd }}$ edn, Blackwell Scientific Publisher, Oxford.

Tice JA, Cummings SR, Smith-Bindman R, et al (2008). Using clinical factors and mammographic breast density to estimate breast cancer risk: development and validation of a new predictive model. Ann Intern Med, 148, 337-47.

Tice JA, Cummings SR, Ziv E, et al (2005). Mammographic breast density and the gail model for breast cancer risk prediction in a screening population. Breast Cancer Res Treat, 94, 115-22.

U.S.Preventive Services Task Force (2009). Screening for breast cancer: u.s. preventive services task force recommendation statement. Ann Intern Med, 151, 716-236.

Yaffe MJ (2008). Mammographic density. Measurement of mammographic density. Breast Cancer Res, 10, 209. 